\title{
HIV risk perception and consistency in condom use among adolescents and young adults in urban Cape Town, South Africa: a cumulative risk analysis
}

\author{
Evans Muchiria*, Clifford Odimegwu ${ }^{\mathrm{a}}$ and Nicole De Wet ${ }^{\mathrm{a}}$ \\ ${ }^{a}$ Demography and Population Studies Programme, Schools of Public Health and Social Sciences, University of the Witwatersrand, Johannesburg, \\ South Africa
}

*Corresponding author, email: EMuchiri@live.co.uk

Background: The relationship between HIV risk perception and consistency in the use of condoms is scarcely understood in the context of a high HIV prevalence among adolescents and young adults in urban South Africa.

Methods: Using data from Cape Area Panel Study (CAPS), gender-stratified analyses were conducted to determine relationship between risk perception and condom use among $14-22$ year olds $(n=4853)$ in urban Cape Town. Using discriminant function analyses, ecological determinants of consistency in condom use were determined and a cumulative risk approach examined. Results: A total of 1598 sexually active youths, of mean age 17.7 years, with 785 (49\%) of males and 813 (51\%) females were identified for analyses. At baseline, $87 \%$ of males and $90 \%$ of females assessed themselves to be at no or low risk of HIV infection. At follow-up, $61 \%$ of males reporting low or no risk were consistently using condoms compared to $67 \%$ reporting some risk of HIV infection. In females, $47 \%$ reporting low or no risk consistently used condoms compared to $49 \%$ of those reporting to be at some risk.

Conclusions: Perceived risk for HIV infection had no significant impact on consistency in using condoms for both males and females. Further, findings suggests that the effect of ecological risk factors was cumulative. Therefore, interventions aimed at the three levels ecology may be more effective in improving consistency as risk factors possess a cumulative effect.

Keywords: adolescents and young adults, condom use, consistency, HIV and AIDS, risk perception, teenage pregnancy

\section{Introduction}

Adolescents and young adults (10-24 years) in South Africa disproportionally share the burden of the HIV and AIDS epidemic with the country reporting the highest number of youths living with HIV globally in 2013. ${ }^{1,2}$ Although recent trends may indicate a stable epidemic, deaths related to HIV among adolescents (1019 years) may in fact be increasing according to the UNAIDS. ${ }^{3}$ In 2013, HIV prevalence among youths aged $15-24$ years in South Africa was estimated at $7.3 \%{ }^{4}$ There is consensus that teenage pregnancy is also a social phenomenon in South Africa. Even though total fertility in South Africa has declined over time, more than $30 \%$ of South African youths gave birth before the age of 20 years in 2008. ${ }^{5,6}$ HIV infection and unwanted underage pregnancy have important implications for demographic outcomes including mortality and fertility. Further, teenage pregnancy disrupts learning opportunities, denying young women of crucial training required for future productivity and may delay achieving a demographic dividend of a country.

Sexual risky behaviours of unprotected sexual activity may increase the risk of unwanted pregnancy, HIV infection and other sexually transmitted infections (STIs) among young people. ${ }^{8-11}$ The impact of HIV and AIDS, and underage pregnancy on aspects of population in a country are profound. People living with HIV and AIDS are more susceptible to developing opportunistic infections, increasing mortality rates among those affected, and reducing life expectancy. In Lesotho for example where an estimated $25 \%$ of the population were living with HIV, life expectancy in the period 1990-1995 was estimated at 60 years, reducing to 34 years in the period 2005-2010 due to increased mortality from HIV and AIDS. ${ }^{12}$

Studies in South Africa have suggested that levels of unsafe sexual activity among adolescents and young adults may be high. ${ }^{13,14}$ According to the South African household survey on HIV prevalence, incidence, and behavior report released by Human Sciences Research Council (HSRC) of 2012, increasing number of adolescents initiate sexual activities early, with multiple partners, and inconsistently use condoms. ${ }^{1,2,15}$ In 2012, it was estimated that $67.5 \%$ of young men aged between 15 and 24 years reported using condoms at their last sexual encounter, down from $85.2 \%$ in 2008 . Condom use among men aged 25 to 49 years also fell from $44.1 \%$ to $36.1 \%$ over the same period.

Correct and consistent use of condoms has been found to be effective in preventing heterosexually transmitted HIV and STIs by more than $90 \% .{ }^{13,16}$ Using condoms also provides a safe family planning option that has no known side effects, thus providing dual protection against unwanted pregnancies and STIs. Globally, condom programs are recommended as highly effective in preventing HIV transmission, adolescence pregnancy, and are generally regarded as acceptable to young people. ${ }^{17}$ However, despite the effectiveness of condoms in preventing unwanted pregnancies and STIs, condom use in South Africa has been described as declining among youths, and calls for a better understanding of how condoms fit within sexual practices. ${ }^{18-20}$

In sub-Saharan Africa, the lethality of AIDS and risk of HIV acquisition in unprotected sex is almost universally known. The health-related behaviour model recognises that perception of being at risk as one of the necessary condition for adopting preventive behaviours. Evidence on the relationship between risk perception and protective behaviour of using condoms is scarce in South Africa. Among youths in countries of sub-Saharan Africa, namely Madagascar, Ghana, and Cameroon, it was observed that perceived risk of HIV infection was associated with an increase in condom use, ${ }^{21-23}$ even though the results were only significant when looking at males with casual partners. In 
Mozambique, a study among 15-24 year old youths found a relationship between correct HIV risk assessment and increased use of condoms in youths who had never married. ${ }^{24}$

In South Africa, condom use has been observed to be low among clinic attendees in high HIV prevalence settings of KwaZuluNatal province despite being informed of the benefits of using condoms..$^{25}$ Even with high levels of HIV/AIDS awareness, selfperceived risk of HIV infection was low and condom use was infrequent. Among married or cohabiting couples residing in KwaZulu-Natal province, a woman's perceived risk of HIV infection from her partner was the most powerful predictor of condom use. ${ }^{26}$ In focus groups conducted among young men and women in the 13-25 year group, factors hindering condom use included lack of perceived risk of HIV infection among others. ${ }^{13}$ Despite the apparent risk posed by inconsistency in condom use among South African youths, there is scarce evidence describing self-risk perception and consistency in using condoms among adolescents and young people. Even though the Western Cape province reports the lowest HIV prevalence of all South African provinces, prevalence of teenage childbearing is a major challenge and points to high levels of unprotected sexual activities. ${ }^{27}$ More than any other region of South Africa, urban Cape Town consistently reports disparities in earnings and income, and poor education outcomes among the African and Coloured populations. ${ }^{28,29}$ The pronounced socioeconomic disparities expose disadvantaged adolescents to a variety of risk factors for sexual behaviours. The use of the Cape Area Panel Study (CAPS) data provides an ideal opportunity to study determinants of risky sexual behaviours among diverse populations and in settings with high socio-economic inequality. Other studies have described risk factors for condom use in isolation, without assessing the cumulative risk of factors occurring at the individual, household, and community levels. As a result, reasons behind the low utilisation of condoms and the high spread of HIV infection in South Africa may not have been well understood, limiting a holistic approach to HIV prevention especially among young people including adolescents and young adults.

In South Africa, findings related to condom use among adolescents and young adults have important implications in the field of demography, due to the effect of HIV infection and teenage pregnancy on fertility and population sizes. In addition, mortality rates among people living with HIV are significantly higher, compared to the general population and greatly impacts on demographic trends. In this paper, risk factors for condom use are reported, specifically examining the role of perceived risk of HIV infection on consistency in the use of condoms. In addition, other factors including the role of household and community level variables, including socio-economic indicators of income and parental relationship are examined. Adolescents and young adults develop in a context referred to as the ecology, defined as a set of nested structures, arranged from closest to the individual level characteristics, then the familial level, to the farthest that was the community level. Factors occurring at these levels have the ability to impact on the sexual behaviour of adolescents and young adults. Ecological perspective integrates risk factors at various levels of the context, suggesting that there exist multiple risk factors related to condom use, and that these risk factors occur at the individual, household, and community levels. The cumulative risk approach assumes that the effect of ecological factors tend to be cumulative implying that the risk of reporting inconsistency in condom use increases with the presence of increasing significant risk factors.

\section{Data and methods}

This paper utilised the Cape Area Panel Study (CAPS) data that includes five rounds of surveys. The CAPS is an ongoing longitudinal survey focusing on a wide range of sexual and reproductive health issues affecting young adults and interviewed about 4800 young adults in urban Cape Town. The baseline survey was conducted in 2002 for Wave 1, and subsequent surveys were conducted for Wave 2a/2b in 2003 and 2004, Wave 3 in 2005, Wave 4 in 2006, and Wave 5 in 2009. The sampling plan was designed to produce a household sample that was representative of households and a young adult sample that was representative of the population aged between 14 and 22 years-old in urban Cape Town. ${ }^{30}$ An adapted ecological systems framework was used to organise risk factors according to levels of ecology including factors at individual, household, and community levels. Risk factors were considered to occur in the ecology where growth and development of adolescent and young adults occurs.

Statistical analysis and data manipulation were carried out in STATA version 13 (STATA Corporation, College Station, TX, USA). A longitudinal analyses data-set was defined for outcomes of inconsistency in condom use and HIV risk perception with analyses conducted separately for males and females. Bivariate analyses were conducted using chi-square tests, and discriminant function analysis for univariate and multivariate analysis. The level of significance was set at $p<0.05$ in both bivariate and multivariate analysis. Risk factors that were significant at the multivariate analyses were used to generate a cumulative risk index, which was used to assess whether significant risk factors had a cumulative effect on inconsistency in the use of condom. This approach assessed whether increasing risk factors were positively correlated with increasing reports in inconsistency on the use of condoms. Cumulative risk indices were generated by summing binary scores from significant risk factors identified for each of the respondent. Included risk factors were scored as either 0 (if risk was absent) or 1 (if risk was present) using designated cut-off points. Proportion reporting inconsistencies in condom use were plotted against the cumulative risk indices for males and females.

Consistency in the use of condoms was defined as always using condoms with the last sexual partner among sexually active respondents during follow-up surveys. Respondents were asked how often they used condoms in their last sexual encounter. Expected responses were either 'always', 'usually', 'sometimes', and 'rarely'. In these analyses, participants responding 'always' in all waves of the survey were considered to be consistent condom users, while the comparison group of inconsistent responded with 'usually', 'sometimes', and 'rarely'.

\section{Results}

Baseline characteristics at Wave 1 survey indicate that 1121 adolescents and young adults had initiated sexual activities, with 911 (81\%) reporting using condoms at the first time of having sex. Male condoms were predominantly used compared to female condoms, with only 3 respondents using female condoms. Results indicate a decline in consistency in condom use between Wave 1 and Wave 3 surveys. At Wave 1, consistency in condom use among males was reported at $72 \%$ compared to $57 \%$ at Wave 3, while in females consistency was reported at $66 \%$ at Wave 1 compared to $37 \%$ at Wave 3 .

From Wave 1 survey, 3415 youths were followed with only 1598 responding to condom use indicators at Wave 2 and Wave 3 , and 
were selected for these analyses. Youths meeting inclusion criteria were grouped as either using condoms consistently or inconsistently, with 866 (54\%) classified as consistent users and $732(46 \%)$ classified as inconsistent. Of the consistent users, stratified analyses by gender indicate that males had a higher proportion reporting consistency at $62 \%$ compared to females at only $47 \%$, findings that were significant at $p<0.01$. Consistency in condom use did not differ significantly between alcohol users and non-users, with $55 \%$ of alcohol users reporting consistency compared to $54 \%$ in non-users.

In males, of the 650 perceiving themselves to be at low or no risk of HIV infection at baseline, $61 \%$ were consistent users of condoms by the end of follow-up. This is in comparison to $67 \%$ consistently using condoms of the 100 males reporting to be at some risk of HIV infection at baseline. In females, of the 695 perceiving themselves to be at low or no risk of HIV infection, $47 \%$ reported consistently using condoms at follow-up compared to $49 \%$ of the 80 females who considered themselves to be at some risk. Findings indicate that HIV risk perception was not a significant determinant of condom use at follow-up, even though for males and females reporting to be at some risk of HIV infection, reported higher proportions of condom use.

The bivariate relationships shows a number of factors associated with consistency in the use of condom as reported on Table 1. In males, significant factors at the individual level include age, where younger adolescents were more likely to consistently use condoms $(p<0.01)$. Currently being enrolled in a school was positively associated with consistency $(p=0.01)$, while expecting to marry in the near future was negatively associated with consistency in condoms use. At the household level, more education among parents was associated with consistency in the use condoms, even though these differences were not pronounced. At the community level, proportion of household heads unemployed and community mean schooling years were also important factors of condom use.

Table 1: Bivariate association between selected risk factors and consistency in use of condoms

\begin{tabular}{|c|c|c|c|c|c|c|}
\hline \multirow[t]{2}{*}{ Independent variables } & \multicolumn{3}{|c|}{ Males $(n=785)$} & \multicolumn{3}{|c|}{ Females $(n=813)$} \\
\hline & Always & Inconsistent & $p$-value & Always & Inconsistent & $p$-value \\
\hline \multicolumn{7}{|l|}{ Individual } \\
\hline HIV Risk perception & & & 0.28 & & & 0.81 \\
\hline No or small risk; $n(\%)$ & $399(61)$ & 251(39) & & $329(47)$ & $366(53)$ & \\
\hline Moderate or great risk; $n$ (\%) & $67(67)$ & $33(33)$ & & $39(49)$ & $41(51)$ & \\
\hline Age (mean years) & 17.54 & 18.27 & $<0.01$ & 17.36 & 17.74 & 0.02 \\
\hline Educational Level (mean years) & 9.29 & 9.18 & 0.56 & 9.58 & 9.66 & 0.64 \\
\hline Currently in school; $n$, (\% yes) & $337(69)$ & $174(59)$ & 0.01 & $303(80)$ & $292(67)$ & $<0.01$ \\
\hline Plan to pass matric first time; $n$ (\% yes) & 298(81) & $173(79)$ & 0.45 & 249(94) & $252(84)$ & $<0.01$ \\
\hline Population group* & & & 0.67 & & & $<0.01$ \\
\hline Black/African; $n(\%)$ & $233(62)$ & $145(38)$ & & $243(53)$ & $217(47)$ & \\
\hline White; $n(\%)$ & $43(67)$ & $21(33)$ & & $49(70)$ & $21(30)$ & \\
\hline Can one protect against HIV; $n$ (\% yes) & $467(97)$ & 279(95) & 0.19 & $366(98)$ & 407(95) & 0.08 \\
\hline Knows someone with HIV; $n$ (\% yes) & $57(12)$ & $48(16)$ & 0.07 & $81(21)$ & $83(19)$ & 0.39 \\
\hline Worked in the last 12 months; $n$ (\% yes) & $131(27)$ & $94(32)$ & 0.16 & $74(20)$ & $97(22)$ & 0.32 \\
\hline Expects to have a job in 3 years** & 3.07 & 3.23 & 0.12 & 2.98 & 3.22 & 0.01 \\
\hline Religiosity; n (\% yes) & $117(24)$ & $58(19)$ & 0.13 & 154(41) & 136(32) & 0.01 \\
\hline Alcohol Use; $n(\%)$ & $121(25)$ & $89(30)$ & 0.11 & $63(17)$ & $62(14)$ & 0.33 \\
\hline Expects to marry in 3 years; $n$ (\% yes) & 13(3) & $16(5)$ & 0.05 & $9(2)$ & $25(6)$ & 0.02 \\
\hline \multicolumn{7}{|l|}{ Household } \\
\hline Parents married; $n$ (\% yes) & $354(73)$ & $227(77)$ & 0.22 & $259(69)$ & $308(71)$ & 0.45 \\
\hline Years of mother's education (mean) & 9.5 & 8.6 & 0.38 & 9.7 & 8.5 & 0.05 \\
\hline Mother a household member; $n$ (\% yes) & $358(74)$ & $230(77)$ & 0.25 & $259(68)$ & $316(73)$ & 0.16 \\
\hline \multicolumn{7}{|l|}{ Community } \\
\hline$\% \mathrm{HH}$ heads unemployed & 19.3 & 21.1 & 0.04 & 22.4 & 21.3 & 0.24 \\
\hline$\% \mathrm{HH}$ headed by females & 39.9 & 40.7 & 0.16 & 41.2 & 41.4 & 0.90 \\
\hline$\%$ Individual Africans & 47.7 & 49.9 & 0.47 & 63.5 & 50.5 & $<0.01$ \\
\hline Mean HH incomes (ZAR) & 58000 & 50000 & 0.07 & 55000 & 48000 & 0.70 \\
\hline Mean schooling years & 9.4 & 9.2 & 0.04 & 9.5 & 9.1 & $<0.01$ \\
\hline
\end{tabular}

*Population group $(1=$ Black, $2=$ Coloured, $3=$ White $)$.

**A scale ranging from 1 (low) to 5 (high). 
In females, younger adolescents, and those currently enrolled in school reported a higher likelihood of consistently using condoms. Positive academic outlook and future prospects of employment were also positively correlated to consistency in using condoms, while planning to marry in the coming years was not. At the household level, a higher level of parental education, and having siblings helping with homework were associated with consistency. At the community level, the proportion of individual Africans living in the area and the mean schooling years were significant factors.

\section{Univariate and multivariate discriminant analyses}

Table 2 reports on the univariate and multivariate results of determinants of consistency in condom use. Results from discriminant function analyses shows that HIV risk perception were not significant determinants for condom use for both males and females in the multivariate model. For males, a total of four risk factors were significantly different between respondents reporting consistency and inconsistency in condom use. Younger males reported being more consistent compared to their older counterparts, while a higher proportion of those consistently using condoms were currently in school. Those consistently using condoms also did not have plans to marry in the immediate future, while those strongly expecting to marry in the next three years were more unlikely to always use condoms in sexual relations with their partners. No risk factors were found to be significantly different at the household level, while at the community level, the mean schooling years of the community significantly different, as young males who were more consistent in using condoms came from communities with a higher mean level of education.

In females, five factors were significantly different between those reporting consistent condom use and those reporting inconsistent condom use. At the individual level, younger females were more likely to be consistent condom users compared to their older counterparts. Also, a high proportion of those reporting consistently using condoms had plans to pass their matric exams compared to those reporting inconsistency. At the household level, females reporting consistency in the use of condoms had on average more educated mothers, and reported more receiving help from siblings with homework. At the community level, females coming from communities with a higher mean level of education were more likely to report consistency in using condoms.

Results from the multivariate analyses indicate that risk factors occurred at the various levels of ecology even though perceived

Table 2: Multivariate discriminant function analysis results

\begin{tabular}{|c|c|c|c|c|c|c|c|c|c|c|}
\hline \multirow{2}{*}{ Independent variables } & \multicolumn{5}{|c|}{ Males } & \multicolumn{5}{|c|}{ Females } \\
\hline & Always & Inconsistent & F-value & $p$-value * & $\mathrm{DA}^{* *}$ & Always & Inconsistent & F-value & $p$-value* & $\mathrm{DA}^{* *}$ \\
\hline \multicolumn{11}{|l|}{ Individual } \\
\hline $\begin{array}{l}\text { HIV risk perception (\% mod- } \\
\text { erate/great) }\end{array}$ & 14 & 11 & 1.16 & 0.28 & & 10 & 10 & 0.06 & 0.81 & \\
\hline Age (mean years) & 17.54 & 18.27 & 5.89 & 0.01 & 0.69 & 17.36 & 17.74 & 18.81 & $<0.01$ & 0.38 \\
\hline Currently in school (\% Yes) & 69 & 59 & 9.24 & $<0.01$ & -0.20 & 80 & 67 & 17.02 & $<0.01$ & \\
\hline Plans to pass matric (\% Yes) & 89 & 89 & 0.01 & 0.91 & & 97 & 89 & 13.36 & $<0.01$ & -0.46 \\
\hline Black African (\% Yes) & 48 & 48 & 0.30 & 0.57 & & 64 & 50 & 1.74 & 0.18 & \\
\hline $\begin{array}{l}\text { Knows someone with HIV } \\
\text { (\% Yes) }\end{array}$ & 11 & 16 & 3.40 & 0.03 & & 21 & 19 & 3.15 & 0.07 & \\
\hline $\begin{array}{l}\text { Expects a job in } 3 \text { years (very } \\
\text { high) }\end{array}$ & 15 & 22 & 2.36 & 0.12 & & 18 & 21 & 5.67 & 0.02 & \\
\hline Expects to marry in 3 years & 3 & 5 & 3.81 & 0.05 & 0.19 & 2 & 6 & 5.92 & 0.01 & \\
\hline Alcohol use & 25 & 30 & 2.50 & 0.11 & & 16 & 14 & 0.91 & 0.33 & \\
\hline Religious (\% Yes) & 24 & 19 & 2.22 & 0.13 & & 40 & 31 & 7.27 & $<0.01$ & \\
\hline \multicolumn{11}{|l|}{ Household } \\
\hline Parents married (\% yes) & 73 & 77 & 1.48 & 0.22 & & 69 & 71 & 0.55 & 0.45 & \\
\hline $\begin{array}{l}\text { Mother's education (Years, } \\
\text { SD) }\end{array}$ & 9.47 & 8.62 & 0.79 & 0.38 & & 9.69 & 8.48 & 3.70 & 0.05 & -0.42 \\
\hline $\begin{array}{l}\text { Father's education (mean, } \\
\text { SD) }\end{array}$ & 10.04 & 8.71 & 2.54 & 0.11 & & 10.33 & 8.22 & 6.37 & 0.01 & \\
\hline $\begin{array}{l}\text { Sibling helps with homework } \\
\text { (\% Yes) }\end{array}$ & 13 & 13 & 0.01 & 0.97 & & 21 & 14 & 7.53 & $<0.01$ & 0.30 \\
\hline Mother a HH member (\% Yes) & 73 & 77 & 1.32 & 0.25 & & 68 & 72 & 1.95 & 0.16 & \\
\hline \multicolumn{11}{|l|}{ Community } \\
\hline$\% \mathrm{HH}$ heads unemployed & 19.3 & 21.1 & 3.79 & 0.05 & & 22.4 & 21.3 & 1.62 & 0.20 & \\
\hline$\% \mathrm{HH}$ headed by females & 39.9 & 40.7 & 0.76 & 0.38 & & 41.2 & 41.4 & 0.03 & 0.84 & \\
\hline$\%$ Individual Africans & 47.7 & 49.9 & 0.42 & 0.51 & & 63.5 & 50.5 & 15.56 & $<0.01$ & \\
\hline Mean HH incomes (ZAR) & 57700 & 49700 & 2.73 & 0.09 & & 54700 & 47800 & 2.70 & 0.10 & \\
\hline Mean schooling years & 9.4 & 9.2 & 5.68 & 0.01 & -0.49 & 9.5 & 9.1 & 21 & $<0.01$ & -0.44 \\
\hline
\end{tabular}

${ }^{*} p$-value for risk factor adjusted for age of the young adult.

**Discriminant function coefficient for factors significant at the multivariate model. 


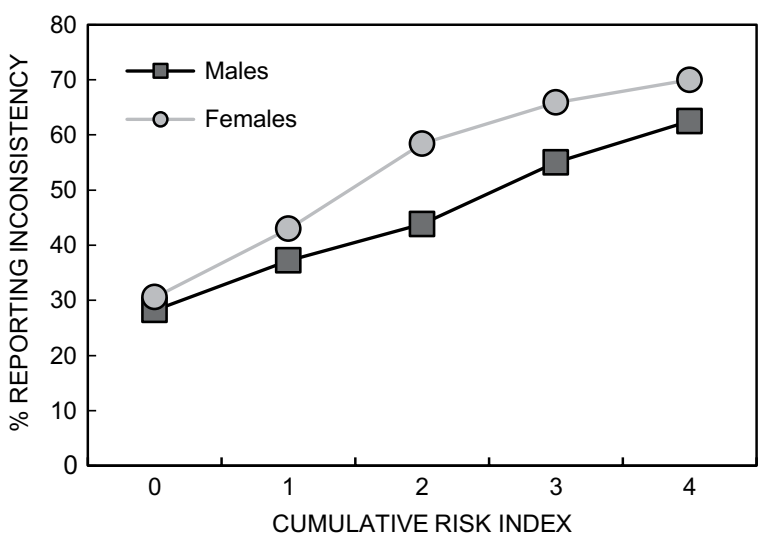

Figure 1: Inconsistency in condom use against present risk factors.

risk of HIV infection was not a significant for consistency in condom use for both males and females.

\section{Assessment of cumulative risk}

Further assessment was conducted to understand whether significant factors obtained from multivariate models were acting cumulatively by constructing a cumulative risk index. For males, four factors were significant in the multivariate analyses including age, currently enrolled in school, expecting to marry in three years, and mean schooling years of the community. For females, the five risk factors included age, plans to pass matric examinations, mother's education level, siblings helping with homework, and mean schooling years of the community.

Figure 1 shows the relationship between risk factors and the proportion reporting inconsistency in the use of condoms. Linear relationships were observed between increasing risk factors present and increasing report of inconsistency in using condoms for both males and females. Results from conducting a simple linear regression between proportion reporting inconsistency and cumulative risk accounted for over $99 \%$ of the variability in the proportion reporting inconsistency in males. This finding was highly significant with $p<0.01$. Similarly, for females, the cumulative risk accounted for over $94 \%$ of the variability that was also highly significant with $p<0.01$. Therefore, these findings suggest that increasing risk factors in the ecology of adolescents and young adults increases reports of inconsistency in the use of condoms.

\section{Discussion}

This study examined the relationship between HIV risk perception and consistency in condom use. It also reported on levels, trends, and determinants of consistency among adolescents and young adults in urban Cape Town, South Africa, and whether the effect of ecological risk factors was cumulative. The study found no significant relationship between respondent's perceived risk of HIV infection with consistency in the use of condoms for both males and females. This is the case where in males and females, perceiving oneself to be at risk of HIV infection had no significant influence on consistently using condoms. However, levels of condom use were reportedly high at the first time of sex using predominantly male condoms. Respondents mainly used condoms for prevention of unwanted pregnancies and STIs

Trends for consistency in condom use decline with age, and condom use is reportedly lower in females than in males. Similar findings have been reported in surveys among young adults residing in Johannesburg, Cape Town, and Durban, which are major cities in South Africa with varying contexts. ${ }^{2}$

Factors associated with consistency in condom use include younger age, where younger males and female respondents were more consistent. Studies have reported that increasing age, frequent sex and longer relationship duration have been associated with reduced consistency in condom use in South Africa. It is unclear why younger respondents were more likely to consistently use condoms, and may suggest that older respondents may be in more stable relationships with plans to marry. This study found that condom use was less consistent among adolescents and young adults planning to marry in the immediate future. These findings have also been reported in other studies where efficacy in condom use has been associated with a decreasing age. ${ }^{31}$

For both males and females, being currently enrolled in school, and planning to pass matric exams were significant factors associated with consistency in using condoms. It is unclear if respondents attending schools were exposed to sex education that contributed to marginal differences observed. Previous research has reported that being in school and having a positive outlook on life delayed sexual activities and could reduce risky behaviour. Also, expecting to marry in the near future was a significant factor for both males and females, predicting a reduction in condom use. Previous research has found that for males and females in stable relationships and preparing for marriages, condom use was low and sexual activities were frequent. ${ }^{31}$ Overall, results indicate that four risk factors for males and five risk factors for females significantly predicted consistency in the use of condoms.

Assessing the cumulative risk of present risk factors on inconsistency in the use of condoms investigated in this study, this study found that as more risk factors become present, the risk of reporting inconsistency increases. The study found a positive linear correlation between number of risk factors present and proportion reporting inconsistency. This may suggest that the effect of risk factors was cumulative in predicting condom use among adolescents and young adults.

As a result of analysing secondary data, this study was limited in that the correlation of condom use responses and partner types could not be further interrogated. Studies have suggested that consistency in condom use may differ by partner type, and asking about condom usage at the last sexual encounter without clarifying the partner type may produce biased responses. The response variable regarding condom use at the last sexual encounter may be different depending on partner type; and, therefore, these findings may contribute to the broad literature on condom use in South Africa, and should be interpreted within the context of related literature.

\section{Conclusion}

This study found that perceived risk of HIV infection was not a significant determinant of consistency in condom using condoms. Results indicating that consistency of condom use declined with increasing age calls for further analysis, and is important to understand in the context of a high HIV prevalence. Further, findings show that risk factors for condom usage are mainly at the individual level, suggesting that to improve consistency, programs need to target mainly the individual and self-efficacy of using condoms. 
Results from assessing the cumulative risk from ecological risk factors indicate that increasing risk factors in the ecology of the young adult exacerbates the risk of engaging in unprotected sex. Therefore, a holistic approach that provides comprehensive programs with incentives both at the individual, household, and community aspects may be more effective. Intervention programs to improve condom use among adolescents and young adults could include cash handouts especially to young females, and incorporating programs that support both young males and females to remain in school. These programs have been found to be effective in India, and parts of KwaZulu-Natal, and have potential to work for Cape Town and South Africa in general.

Acknowledgements - The Cape Area Panel Study Waves 1-2-3 were collected between 2002 and 2005 by the University of Cape Town and the University of Michigan, with funding provided by the US National Institute for Child Health and Human Development and the Andrew W Mellon Foundation. Wave 4 was collected in 2006 by the University of Cape Town, University of Michigan and Princeton University. Major funding for Wave 4 was provided by the National Institute on Aging through a grant to Princeton University, in addition to funding provided by NICHD through the University of Michigan.

Authors' contributions - CO, NDW and EM conceived this article. EM did the literature review and analysed the CAPS data. All authors have read and approved the final manuscript.

\section{References}

1. Shisana O, Rehle T, Simbayi L, et al. South African National HIV prevalence, HIV incidence and behaviour and communication survey, 2008: a turning tide among teenagers?. CapeTown: HSRC Press; 2009.

2. Shisana O, Rehle T, Simbayi LC, et al. South African National HIV Prevalence, Incidence and Behaviour Survey, 2012. Cape Town: HSRC HSRC Press; 2014.

3. UNAIDS. The Gap Report. Joint United Nations Programme on HIV/ AIDS. 2014. Geneva, Switzerland.

4. UNAIDS. Report on the Global AIDS Epidemic. 2013. Geneva: UNAIDS.

5. Panday S, Makiwane M, Ranchod C, et al. Teenage pregnancy in South Africa - with a specific focus on school-going learners. Child, youth, family and social development, human sciences research council. Pretoria: Department of Basic Education. 2009.

6. Willan S. A review of teenage pregnancy in South Africa. Parow: Partners in Sexual Health (PSH); 2013.

7. Jewkes R, Morrell R, Christofides N. Empowering teenagers to prevent pregnancy: lessons from South Africa. Culture, Health Sex. 2009;11(7): 675-688. https://doi.org/10.1080/13691050902846452

8. Zuma K, Setswe G, Ketye T, et al. Age at sexual debut: a determinant of multiple partnership among South African youth. Afr J Reprod Health. 2010;14(2): 47-54.

9. Bearinger LH, Sieving RE, Ferguson J, Sharma V. Global perspectives on the sexual and reproductive health of adolescents: patterns, prevention, and potential. Lancet. 2007;369(9568): 1220-31. https://doi.org/10.1016/S0140-6736(07)60367-5

10. McGrath N, Nyirenda M, Hosegood V, Newell ML. Age at first sex in rural South Africa. Sex Trans Infect. 2009;85(Suppl 1): i49-55. https://doi.org/10.1136/sti.2008.033324

11. Zuma K, Mzolo T, Makonko E. Determinants of age at sexual debut and associated risks among South African youths. Afr J AIDS Res 2011;10(3): 189-94. https://doi.org/10.2989/16085906.2011.626283

12. UNPD. UN population division, world population prospects: the 2004 Revision; and UNAIDS, 2006 report on the global AIDS epidemic. 2004. UN, New York, USA.
13. MacPhail C, Campbell C. 'I think condoms are good but, aai, I hate those things': condom use among adolescents and young people in a Southern African township. Soc Sci Med. 2001;52(11): 1613-27. https://doi.org/10.1016/S0277-9536(00)00272-0

14. Eaton L, Flisher AJ, Aaro LE. Unsafe sexual behaviour in South African youth. Soc Sci Med. 2003;56(1): 149-65. https://doi.org/10.1016/ S0277-9536(02)00017-5

15. Kaplan DL, Jones EJ, Olson EC, Yunzal-Butler CB. Early age of first sex and health risk in an urban adolescent population. J School Health. 2013;83(5): 350-56. https://doi.org/10.1111/josh.12038

16. Nyembezi A, Ruiter RA, van den Borne B, et al. Correlates of consistent condom use among recently initiated and traditionally circumcised men in the rural areas of the Eastern Cape Province, South Africa. BMC Public Health. 2014;14: 668. https://doi.org/10.1186/1471-2458-14-668

17. Chandran TM, Berkvens D, Chikobvu P, et al. Predictors of condom use and refusal among the population of Free State province in South Africa. BMC Public Health. 2012;12:381. https://doi.org/10.1186/14712458-12-381

18. Maticka-Tyndale E. Condoms in sub-Saharan Africa. Sex Health. 2012;9(1): 59-72. https://doi.org/10.1071/SH11033

19. Adedimeji AA, Heard NJ, Odutolu O, et al. Social factors, social support and condom use behavior among young urban slum inhabitants in southwest Nigeria. East Afr J Public Health. 2008;5(3): 215-22.

20. Adedimeji AA, Omololu FO, Odutolu O. HIV risk perception and constraints to protective behaviour among young slum dwellers in Ibadan, Nigeria. J Health Popul Nutr. 2007;25(2): 146-57.

21. Meekers D, Klein M, Foyet L. Patterns of HIV risk behavior and condom use among youth in Yaounde and Douala, Cameroon. AIDS Behav. 2003;7(4): 413-420. https://doi.org/10.1023/B:AlBE.0000004733.26053.c8

22. Meekers $D$, Klein $M$. Determinants of condom use among young people in urban Cameroon. Stud Family Plan. 2002;33(4): 335-46. https://doi.org/10.1111/sifp.2002.33.issue-4

23. Wamoyi J, Wight $D$, Remes $P$. The structural influence of family and parenting on young people's sexual and reproductive health in rural northern Tanzania. Culture, Health \& Sex. 2014;17(6): 718-32.

24. Prata N, Morris L, Mazive E, et al. Relationship between HIV risk perception and condom use: evidence from a population-based survey in Mozambique. Int Family Plan Perspect. 2006;32(4): 192-200. https://doi.org/10.1363/3219206

25. Hartung TK, Nash J, Ngubane N, et al. AIDS awareness and sexual behaviour in a high HIV prevalence area in rural northern Kwazulu-Natal, South Africa. Int J STD \& AIDS. 2002;13(12): 829-32. https://doi.org/10.1258/095646202321020107

26. Maharaj P. Reasons for condom use among young people in KwaZuluNatal: prevention of HIV, pregnancy or both? Int Family Plan Perspect. 2006;32(1): 28-34. https://doi.org/10.1363/3202806

27. Dinkelman T, Lam D, Leibbrandt M. Household and community income, economic shocks and risky sexual behavior of young adults: evidence from the Cape Area Panel Study 2002 and 2005. AIDS. 2007;21(Suppl 7): S49-56. https://doi.org/10.1097/01.aids.0000300535.05226.a9

28. Kleinschmidt I, Pettifor A, Morris N, et al. Geographic distribution of human immunodeficiency virus in South Africa. Am J Tropical Med Hyg 2007;77(6): 1163-69.

29. Lopman B, Lewis J, Nyamukapa C, et al. HIV incidence and poverty in Manicaland, Zimbabwe: is HIV becoming a disease of the poor? AIDS. 2007;21(Suppl 7): S57-66. https://doi.org/10.1097/01. aids.0000300536.82354.52

30. Lam, D, Ardington, C, Branson, N, et al. The cape area panel study: A very short introduction to the integrated waves 1-2-3-4 data. Rondebosch: The University of Cape Town. 2008.

31. Hendriksen ES, Pettifor A, LeeSJ, et al.Predictors of condom use among young adults in South Africa: the reproductive health and HIV research unit national youth survey. Am J. Public Health. 2007;97(7): 1241-48. https://doi.org/10.2105/AJPH.2006.086009

Received: 22-07-2016 Accepted: 17-05-2017 